DE DE GRUYTER OPEN
UDC: $621.31: 336.055$

DOI: 10.2478/jcbtp-2014-0004
Journal of Central Banking Theory and Practice, 2014, Vol.3 No.1, pp. 43-58

Received: 18 November 2013; accepted: 29 November 2013.

\section{Relationship Between Energy Prices, Monetary Policy and Inflation; A Case Study of South Asian Economies}

${ }^{*}$ International Institute

of Islamic Economics,

International Islamic

University, Islamabad

E-mail:

atiqurrehman@iiu.edu.pk

ateeqmzd@gmail.com

\begin{abstract}
Monetary policy tools, including money supply and interest rate, are the most popular instruments to control inflation around the globe. It is assumed that a tight monetary policy, either in form of reduction in money supply or an increase in interest rate, will reduce inflation by reducing aggregate demand in an economy. However, monetary policy could be counterproductive if cost side effects of monetary tightening prevail. High energy prices may increase the cost of production by reducing aggregate supply in the economy. If tight monetary policy is used to reduce this cost push inflation, the cost side effect of energy prices will add to cost side effects of monetary tightening and will become dominant. In this case, the monetary policy could be counterproductive. Furthermore, simultaneous reduction in aggregate supply and aggregate demand will bring twofold reduction in output. Therefore greater care is needed in the use of monetary policy in the situation of cost push inflation. This article investigates the presence of cost side effect of monetary transmission mechanism, the role of international oil prices in domestic inflation, and implications for monetary policy. The findings suggest that both monetary policy and oil prices have cost side effects on inflation and monetary tightening could be counterproductive if used to reduce energy pushed inflationary trend.
\end{abstract}

Keywords: Oil Price, Inflation, Monetary Policy, Cost Channel, Demand Channel

JEL Classification: E50, E52, E58 


\section{Introduction}

Monetary tightening is the most popular tool used by central banks to control inflation throughout the globe. The most common perception among economists regarding monetary tightening is that monetary tightening would reduce aggregate demand; therefore, the equilibrium price level and output go down. However, in practice, the use of monetary tightening could be counterproductive. The evidence that monetary tightening may increase inflation dates back to 1923 when Gibson (1923) observed that correlation between interest rate and inflation is positive, contrary to the prediction of economic theories. Later on, it was found that monetary tightening, either by a reduction in money supply or by an increase in interest rate, may also affect the economy through cost channel. When a tight monetary policy is used, the cost of hiring working capital increases, resulting in an increased cost of production. In this case, firms may reduce their supply at the existing price level, resulting in a reduction in aggregate supply. This shift in aggregate supply will increase the equilibrium price level and reduce output. Nowadays, economists are discovering a number of other transmission mechanisms through which a monetary policy could affect the output and inflation (see Ghaffari (2013) for a nice discussion). However, the ultimate impact of all these channels will be either through changing aggregate demand or through aggregate supply. The demand side channels suggest a reduction in inflation by a reduction in aggregate demand, whereas the supply side channels suggest an increase in inflation through a reduction in aggregate supply.

In reality, there is no reason to believe that any monetary intervention will have only one side effect. Monetary interventions can act simultaneously through supply and demand channels and, in that case, the net impact on economy could be summarized as follows:

1. If the demand side channels are dominant, then monetary tightening will reduce inflation and output.

2. If the cost side channels are dominant, then monetary tightening will increase inflation and reduce output.

3. If both cost and demand side channels are of same strength, the effect of monetary tightening on inflation will be insignificant and a reduction in output will be twofold.

Suppose the monetary tightening is used to control inflation driven by oil prices - high oil prices increase the cost of fuel/energy used by industry, these additional cost effects add to the cost side effect of monetary transmission mechanism, and the cost effects become dominant. The result will be a reduction in output cou- 
pled with an increase in price level instead of reduction. Therefore, greater care is needed in the use of monetary policy when there is cost push inflation in the economy.

This paper explores the existence of cost side effects of monetary interventions, the role of international oil price in the domestic inflation and impacts of monetary policy in presence of cost push inflation due to high energy prices.

\section{Effects of Monetary Tightening}

The history of a debate over the monetary policy effects is long and inconclusive. The way a monetary policy translates into real variables is called the monetary transmission mechanism. In the early history of monetary policy, there was only one mainstream popular monetary transmission mechanism known as the demand channel of monetary transmission mechanism. The mechanism indicates that a tight monetary policy will reduce inflation by reducing aggregate demand. Therefore, tight monetary policy has become the most frequently used anti-inflation measure. However, the empirical evidence against this perception date way back to Tooke (1838) who argues that prices are determined by the supply side effect rather than monetary variables. Later on it translated into a strong voice against monetary policy and in words of Patman (1974), an American congressman, "the use of tight monetary policy to control inflation is like throwing gasoline on fire". The justification of this opposite view lies in the cost channel. Long discussions on the two channels can be found in literature, e.g. Barth and Ramey (2001), Mishkin (2005), etc.

However, it is also possible that a monetary policy affects an economy through the two channels simultaneously. But a discussion on what will happen if both channels are present in the economy is rarely found in the literature. Ghaffari (2013) discusses the implications of simultaneous effect of cost and demand side effects in his MS thesis. The rest of this section describes how the cost and demand channels will affect an economy and what will happen if the two channels interact. This section graphically explains the demand and cost channels and the possibility of the two channels acting concurrently.

\subsection{Demand Channel of Monetary Transmission Mechanism}

The basic idea behind this channel is: given some degree of price stickiness, a tight monetary policy increases nominal interest rates, which translates into an 
increase in the real rate of interest and the user cost of capital. These changes, in turn, lead to a postponement in consumption or a reduction in investment spending. This will reduce aggregate demand in the economy and, as a result, the equilibrium price level goes down. This view is a present in most of the standard textbooks on macroeconomics and monetary policy and it is the most popular economists' perception of impacts of inflation. This view provides the basis for the Taylor Rule, the rule used by many central banks in creating monetary policy today.

The effect of monetary tightening on prices could be visualized with a help of the following diagrams.

Consider the state of economy where

Figure 1: Effect of Monetary Tightening through the Demand Channel

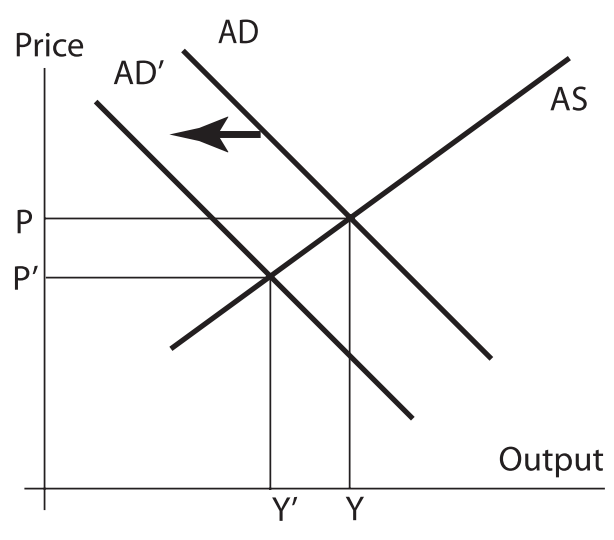

the supply curve is AS and the demand curve is $\mathrm{AD}$. The equilibrium price and output are $\mathrm{Y}$ and $\mathrm{P}$, respectively. Suppose the central bank announces a tighter monetary policy and the monetary tightening acts only through the demand channel. This will shift the demand curve to the left and a new demand curve is AD'. The new equilibrium is achieved at $\left(\mathrm{Y}^{\prime}, \mathrm{P}^{\prime}\right)$ where $\mathrm{Y}^{\prime}<\mathrm{Y}$ and $\mathrm{P}^{\prime}<\mathrm{P}$, i.e. the monetary intervention reduced both the price level and the output. This provides the basis of the so-called Taylor Rule used by central banks to design their monetary policy. This mechanism ignores the cost side effects of the monetary tightening.

\subsection{Cost channel of Monetary Transmission Mechanism}

The empirical evidence against the demand channel can be found way back. Gibson (1916) found that the correlation between interest rate and inflation is positive. This was quite opposite to the perception of economists and therefore taken as a paradox, referred to as the Gibson Paradox by Keynes (1936) or the price puzzle by Sims (1992). Later on, economists Barth \& Ramey (2001), Blinder (1987) and Farmer (1984) found a logical explanation of the so-called Gibson paradox or price puzzle in the form of cost channel of monetary transmission mechanism. 
Over the past 25 years, lots of research has been done on the cost channel and mix evidences have been found for and against the existence of cost channel.

The cost channel states that the cost of hiring working capital increases with monetary tightening, leading to increased cost of production. Therefore, firms may reduce the supply of their products at the existing price level. This reduction in supply may increase the aggregate price level instead of reducing it.

Suppose the monetary intervention acts through the cost channel. In this case, the effect of monetary tightening could be visualized in Figure 2. The economy is at equilibrium (Y, P) before the monetary intervention. The monetary intervention shifts the supply curve to AS' and a new equilibrium is achieved $\left(\mathrm{Y}^{\prime}, \mathrm{P}^{\prime}\right)$ where $\mathrm{Y}^{\prime}<\mathrm{Y}$ and $\mathrm{P}^{\prime}>\mathrm{P}$.

This is the case in which the monetary intervention is counterproductive and resulted in a reduction of output coupled with an increase of the price level. Obviously, this is against the goal of the central bank. Therefore, it is necessary to explore whether the monetary intervention affects the economy through the cost channel or through demand channel so that this undesirable outcome could be avoided.

\subsection{Interaction of cost and demand channels}

Suppose the monetary intervention acts simultaneously through demand and cost channel. The effect of this intervention could be visualized in Figure 3.
Figure 2: Effect of Monetary Tightening through the Cost Channel

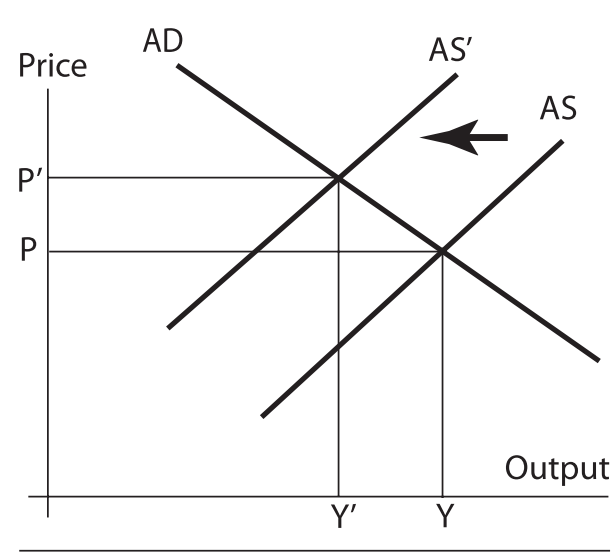

Figure 3: Effect of Monetary Tightening Through Cost and Demand Channel Simultaneously

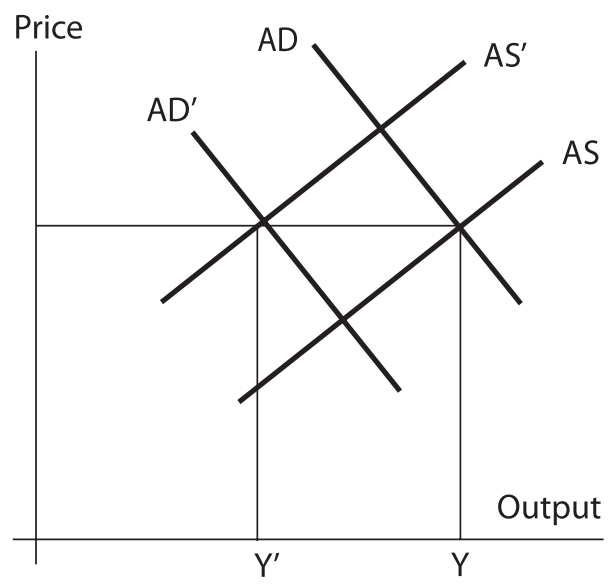


The monetary intervention shifted the aggregate supply curve to AS' and the demand curve to AD'. The resulting equilibrium occurs at (Y'”, $\mathrm{P})$. The price level remains the same after intervention but the output decreases to Y'”. One can see that this reduction in output is larger than the reduction in output caused by the demand channel or the supply channel alone. This monetary tightening will cause a twofold reduction in output without any effect on the price level.

The interaction of cost and demand channels is not found in standard literature; however, there are certain studies whose findings match the effects discussed above. Many studies found that the effect of interest rate increase on prices is insignificant and/or the corresponding effect on output is negative. These studies support the idea that a simultaneous shift in supply and demand curve resulted in no change in prices with reduction in output.

\section{Monetary Tightening in Presence of Energy Price Inflation}

The above discussion suggests that monetary tightening may be useful only if the demand side effect dominate. It would be counterproductive if the cost side effects dominate or if the cost side effect is similar to demand side effects. Since oil and energy are inputs in nearly every industrial output, an increase in energy prices will increase the cost of production. The cost side effects of oil prices will strengthen the cost side effect of monetary transmission mechanism. Therefore, the use of tight monetary policy will be counterproductive.

Suppose monetary intervention is used to reduce oil price inflation in an economy where the demand side of monetary transmission mechanism is prevailing. The prevailing cost side effects of monetary intervention would be strengthened by the cost side effect of oil price shock. The result may be similar to the effect reflected in Figure 3, where monetary tightening only affects the output with no effect on prices.

On the other hand, suppose monetary tightening is used in an economy where the cost side effects are either dominant or equal to the supply side effects; in this case, the cost side effects would become yet stronger with the addition of oil price effects. The results are visualized in Figure 4. The economy is at equilibrium (Y,P) before intervention. The cost side effects created by oil prices shift the supply curve to AS", and the monetary transmission via the cost channel further shifts the supply curve to AS"'. The result is a manifold decrease in output paired with a rise in prices. 
The above discussion shows that monetary tightening in the presence of oil price inflation is counterproductive, regardless of whether the monetary transmission occurs through the demand channel or the cost channel. If the demand channel is the prevailing channel in the economy, the cost side effects of oil price will strengthen the cost side effects of monetary transmission, and results might be similar to the result summarized in Figure 3, i.e. no effect on the prices coupled with a twofold reduction in output. On the other hand, if tight monetary policy is used in an economy with strong cost side effects, the twofold pressure on the supply curve will result in a greater reduction in output and an increase in prices.

The validity of the discussion above depends on two assumptions: (a) there are cost side effects of monetary transmission in the economy (b) the oil prices create a cost push pressure on inflation. In the following sections, I try to explore the validity of these two assumptions for the South Asian Economies.

\section{Data and Methodology}

The empirical part of this paper consist of the following: (a) testing whether or not there are cost side effects in South Asian economies (b) testing whether or not the energy prices (international oil prices) create domestic inflation in the South Asian economies.

To test the existence of the cost channel, the Pearson correlation, the Partial Correlation and the Granger Causality are used. The Granger Causality is used to test the effects of international oil prices on domestic inflation.

\subsection{Testing for unit root}

However, the time series relation has a strong tendency to show spurious correlation if the series are non-stationary and not co-integrated. Therefore, before 
assessing the relationship on the basis of correlations, we have to be sure that the correlation is not spurious. The correlation is not spurious if the two series entering into relationship are stationary. The core variables entering the monetary transmission mechanism are the interest rate, money supply growth and inflation. Since inflation and money supply growth are the rates of change, it is likely that they are stationary. Similarly, the interest rate is unlikely to be unbounded and the unit root series is unbounded. Therefore, the three series could be stationary. However, instead of relying on these theoretical properties, we verify the stationarity of these series by a formal unit root testing. The Phillips Perron test was applied to test for unit root.

\section{THE PHILLIPS-PERRON TEST}

The Phillips-Perron test is a unit root test based on the Dickey-Fuller regression equation. But unlike the Augmented Dickey-Fuller test, which extends the Dickey-Fuller test by including additional lags of variables as regressors in the model, the Phillips-Perron test makes a non-parametric correction to the t-test statistic to capture the effect of autocorrelation.

\section{The Phillips Perron test statistics}

The Phillips Perron test statistics is based on the regression equation described below:

$$
\Delta y_{t}=\alpha+\rho y_{t-1}+e_{t}
$$

Where

$$
e_{t} \sim \text { iid }\left(0, \sigma^{2}\right)
$$

The test statistics is given by:

$$
\widetilde{t}_{\rho}=t_{\hat{\rho}}\left(\frac{s^{2}}{\hat{f}(0)}\right)-T\left(\frac{\left(\hat{f}(0)-s^{2}\right)(S E(\hat{\rho})}{2\left(\hat{f}(0) \sum_{t=2}^{T} e_{t}^{2}\right)^{0.5}}\right)
$$

where $t_{\hat{\rho}}=\frac{\hat{\rho}}{S E(\hat{\rho})}, s^{2}=T^{-1} \sum_{t=2}^{T} e_{t}^{2}$ and $e_{t}$ are the residuals of the regression, $\hat{f}(0)$ is the estimate of spectral density at frequency zero which can be computed as follows: 
Consider the ADF regression equation described in (1). Estimate the number of lags included in the ADF equation using some consistent criterion, e.g. MAIC. Then the estimate of the autoregressive spectral density at frequency zero is given by:

$$
\hat{f}(0)=\frac{\hat{\sigma}^{2}}{\left(1-\hat{\gamma}_{1}-\hat{\gamma}_{2}-\ldots \hat{\gamma}_{k}\right)}
$$

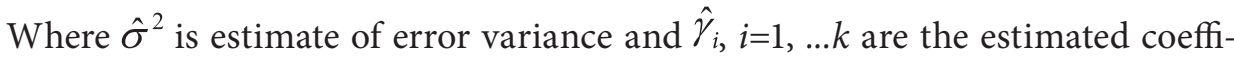
cients from regression eq (1)

\subsection{Testing Granger Causality}

The Granger causality test is based on the following idea. Other things being same, examine whether the past values of cause variables $\mathrm{X}$ has help in predicting the dependent variable $\mathrm{Y}$. If the past values of $\mathrm{X}$ help in predicting, $\mathrm{X}$ is said to Granger Causes Y.

Suppose we want to test whether X Granger Causes on Y or not. Other things remaining same, if the distribution of $Y$ conditional on lag values of $Y$ \& lag values of $\mathrm{X}$ is equal to distribution of $\mathrm{Y}$ conditional on lag, then $\mathrm{X}$ does not Granger Cause Y.

There are various procedures of testing the Granger Causality. The procedure accepted here is as follows:

- Regress $\mathrm{Y}$ on its own lags, lag value of $\mathrm{X}$ and lag value of other control variables

- Test zero restriction on all lags of X via standard LR test

- If the restriction is valid then lag values of $\mathrm{X}$ play no role in determining $\mathrm{Y}$, and $\mathrm{X}$ does not Granger Cause $\mathrm{Y}$.

For the analysis presented in this study, inflation is taken as the dependent variable $\mathrm{Y}$, interest rate and money supply as the independent variables $\mathrm{X}$, and exchange rate as the control variable.

\subsection{Data}

Data on the monetary variables and inflation were obtained from the International Financial Statistics CD ROM (2012), whereas data on the oil prices (dollar per barrel) were obtained from the Wall Street Journal database. The data consist 
of monthly time series for the time span $1980 / 1$ to $2011 / 12$. The T-bill rate was used as a measure of interest rate, M2 as a measure of money supply and CPI as a measure of prices. The rate of growth for CPI and Money supply were used in the analysis instead of level series.

\section{Results and Discussion}

\subsection{Preliminary Data Analysis}

Before starting the data analysis, we have plotted the cross plot of monetary variables versus monthly inflation for various countries. The plots for Pakistan are shown in Figure 5 below. The left panel plots relation between money supply growth and inflation whereas the right panel plots the relation between interest rate and inflation. The scatter plots show that there is neither positive nor negative relation between the monetary variables and inflation for both interest rate and money supply growth.

Figure 5: Monetary Variables versus Inflation for Pakistan
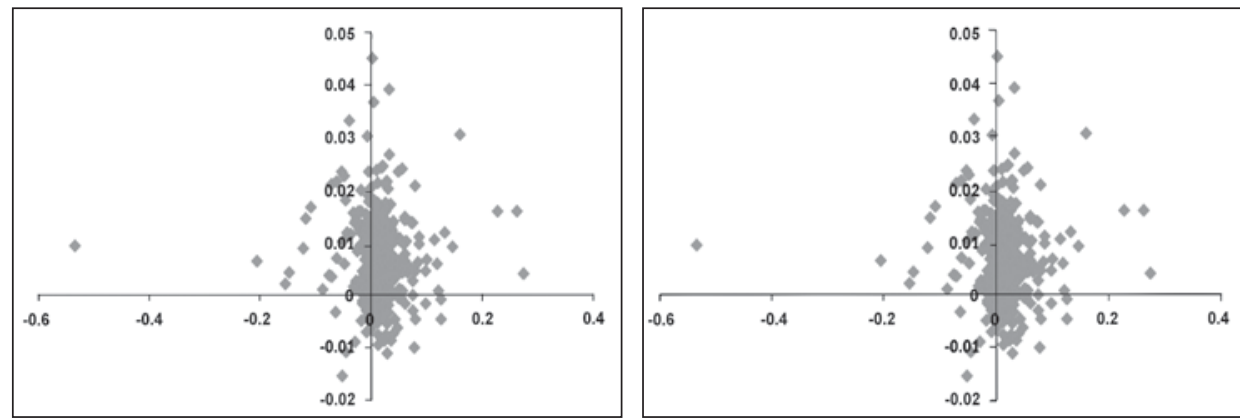

Graphs for the rest of three countries show similar patterns, but are skipped here for the sake of parsimony.

\subsection{Unit Root Test Results}

Before any further analysis, all series were tested for unit root as discussed in section 4. 
Table 1: Results of unit root testing

\begin{tabular}{lcc}
\hline \multicolumn{1}{c}{ Series/Country } & Test Statistics & P-Value \\
\hline Inflation Bangladesh & -10.23 & 0.00 \\
\hline Inflation India & -12.23 & 0.00 \\
\hline Inflation Pakistan & -16.13 & 0.00 \\
\hline Inflation Sri Lanka & -13.12 & 0.00 \\
\hline Money Growth Bangladesh & -32.22 & 0.00 \\
\hline Money Growth India & -27.85 & 0.00 \\
\hline Money Growth Pakistan & -21.48 & 0.00 \\
\hline Money Growth Sri Lanka & -21.61 & 0.00 \\
\hline Interest Rate Bangladesh & -8.25 & 0.00 \\
\hline Interest Rate India & -5.01 & 0.00 \\
\hline Interest Rate Pakistan & -4.57 & 0.01 \\
\hline Interest Rate Sri Lanka & -3.33 & 0.02 \\
\hline
\end{tabular}

The results show that all the series are stationary at level; therefore, any sophisticated econometric analysis on this data is unlikely to be spurious.

\subsection{Are There Cost Side Effects in South Asian Economies?}

If monetary tightening is affecting an economy through the demand channel of monetary transmission mechanism, then the tightening should have a negative effect on inflation. On the other hand, if monetary tightening affects the economy through the cost channel, then tightening should have a positive effect on inflation. Therefore, the correlation between the indicator tightening (reduction in money supply and/or increase in interest rate) can tell us about the dominant channel of monetary transmission mechanism.

Table 1 summarizes the correlation calculated between inflation and two monetary variables, i.e. interest rate and money supply growth for four South Asian economies. We see that the correlation between money supply and inflation is insignificant for all four countries included in the study. This implies that expansion or reduction in money supply has no effect on inflation. This finding contradicts the popular quantity theory of money; however, it has a number of supporting evidence in literature. These results indicate that the demand side and the cost side effect of monetary expansion/tightening probably cancel each other and the net effect of this expansion on inflation is negligible. 
Table 2: Correlation between Monetary Variables and Inflation for South Asian Economies

\begin{tabular}{lcccc}
\hline & Sri Lanka & India & Pakistan & Bangladesh \\
\hline \multirow{2}{*}{ Money Supply Growth } & 0.015 & 0.093 & -0.012 & 0.009 \\
& $(0.78)$ & $(0.07)$ & $(0.82)$ & $(0.86)$ \\
\cline { 1 - 2 } Interest Rate & 0.148 & 0.087 & 0.067 & -0.379 \\
& $(0.00)$ & $(0.09)$ & $(0.19)$ & $(0.00)$ \\
\hline
\end{tabular}

The $p$-values are written in parenthesis

* Indicates significance at 5\% significance level

On the other hand, the correlation between interest rate and inflation is significant for India and Pakistan, positive for Sri Lanka, and negative for Bangladesh. As for Pakistan and India, the results support the conjecture that probably the cost and demand side effects cancel each other and the net effect of monetary tightening is insignificant. These findings also have supporting evidences in literature, e.g. Bernanke and Gertler (1998) and Rehman (2011) found the interest rate to be insignificant in the equation for inflation. For Sri Lanka, the cost side effects appear to prevail, and for Bangladesh, the demand side effect appears to be dominant. This evidence supports the idea that the cost side effects are present in the South Asian economies, however, the costs side effects prevail in Sri Lanka, whereas in Bangladesh, the demand side effects are dominant. For the remaining two countries, i.e. India and Pakistan, two types of effects have roughly the same strength and cancel each other.

However, the analysis presented above might be criticized for ignoring the effect of confounding variables. The following Table depicts a partial correlation between monetary variables and inflation after controlling for effects of confounding variables.

Table 3: Partial Correlation between Monetary Variables and Inflation

\begin{tabular}{lcccc}
\hline & Sri Lanka & India & Pakistan & Bangladesh \\
\hline \multirow{2}{*}{ Money Supply Growth } & -0.004 & 0.095 & -0.012 & 0.001 \\
& $(0.94)$ & $(0.07)$ & $(0.82)$ & $(0.99)$ \\
\cline { 1 - 2 } Interest Rate & 0.134 & 0.031 & 0.059 & -0.157 \\
& $(0.01)$ & $(0.55)$ & $(0.25)$ & $(0.00)$ \\
\hline
\end{tabular}

The $p$-values are written in parenthesis

* Indicates significance at 5\% significance level

The results of partial correlation are quite similar to the results we found from simple correlation analysis. The correlation between money supply and inflation 
is insignificant for all countries included in the study. The relation between interest rate and inflation is positive for Sri Lanka, negative for Bangladesh, and insignificant for Pakistan and India. This adds to the evidence in favour of cancelation of the cost and demand side effects for Pakistan and India.

However, one can argue that there should be a lag between monetary intervention and its impact. It often happens that individuals change their behaviour just on basis of monetary policy statement before the actual implementation of policy. Sometime people change behaviour even before the statement just on the account of their expectations regarding the future policy. If this is the case, then there is no lag between monetary intervention and its output and the analysis above could be valid. However, if the monetary transmission requires some lag, than it could be tested with the Granger Causality. The Granger Causality test can be used to test if the past values of the cause variable $\mathrm{X}$ have any impact on the consequence variable Y. The results of Granger Causality are mentioned in Table 3.

\section{Table 4: F-statistics for the Granger Causality test between Monetary Variables and Inflation}

\begin{tabular}{lcccc}
\hline \multicolumn{1}{c}{ Hypothesis } & Sri Lanka & India & Pakistan & Bangladesh \\
\hline Money Supply Growth Does & 6.194 & 4.533 & 2.557 & 3.194 \\
not Granger Cause Inflation & $(0.40)$ & $(0.60)$ & $(0.86)$ & $(0.78)$ \\
\hline Interest Rate Does not Granger & 13.953 & 2.386 & 16.154 & 10.093 \\
Cause Inflation & $(0.03)$ & $(0.88)$ & $(0.01)$ & $(0.12)$ \\
\hline
\end{tabular}

We see that the results of the Granger Causality match those of the simple correlation for the relationship between money supply and inflation. The null hypothesis that Money supply does not Granger Cause inflation is not rejected for all four countries included in the study. On the other hand, the Granger Causality test for interest rate has some contradiction with the results of simple correlation. For Bangladesh, the correlation between interest rate and inflation was negative, but the interest does not Granger Cause the inflation for Bangladesh. For Pakistan, the correlation between interest rate and inflation was insignificant, but the interest does Granger Cause the inflation for Pakistan. This means that the effects of monetary interventions appear after some lag and that the demand and cost side effects do not cancel each other. However, the Granger Causality test is unable to tell the sign of relation between underlying variables and it is not clear whether the effect of interest on inflation is through cost side or demand side. For finding the dimension of this relation, we calculated the unrestricted ARDL model and the coefficient of long run relationship. The results are reported in Table 4 . The results indicate that the long term relation between the two variables is positive, indicating the dominance of the cost channel of monetary policy. 
Table 5: Static Long Run Relation between Inflation and Interest Rate

\begin{tabular}{cccc}
\hline & Constant & Interest Rate & Money Supply Growth \\
\hline Long Run Relation & 0.00428 & 0.001 & 0.0058 \\
\hline
\end{tabular}

These results imply that the empirical evidence favour the dominance of the cost channel and none of the evidences is found favouring the popular demand side of monetary transmission mechanism. Therefore, the monetary transmission mechanism is counterproductive in its own right and a tight monetary policy increases inflation instead of reducing it.

\subsection{Do the Energy Prices Effect Domestic Inflation?}

Having seen that the cost channel is supported by stronger empirical evidence, it is now important to explore whether or not the international oil prices bring cost push inflation in Pakistan. If the oil prices bring inflation, than the assumption underlying the analysis presented in Sections 2 and 3 is valid and a tight monetary policy is necessarily counterproductive. For this purpose, we test the hypothesis that the international oil prices cause inflation using the popular Granger Causality test. The results are presented in Table 5.

Table 6: F-statistics for the Granger Causality test between Oil Prices and Inflation

\begin{tabular}{lcccc}
\hline \multicolumn{1}{c}{ Hypothesis } & Sri Lanka & India & Pakistan & Bangladesh \\
\hline Oil Prices Do not Granger & 2.81 & 10.84 & 9.10 & 2.74 \\
Cause Inflation & $(0.42)$ & $(0.01)$ & $(0.03)$ & $(0.43)$ \\
\hline
\end{tabular}

The results indicate that there is strong evidence of Causality between the international oil prices and inflation for India and Pakistan. Therefore, if there are high oil prices in the international market, the domestic inflation is likely to be the oil price push inflation and the analysis presented in Sections 2 and section 3 is applicable.

\section{Summary and Conclusion}

In this study we have analyzed a state of economy in which monetary transmission occurs simultaneously through the cost and demand channels. The analysis shows that the impact of monetary intervention depends on relative importance of the cost and demand channels. Monetary tightening may be useful only if the 
demand side effects prevail and would be counterproductive otherwise. The analysis further shows that to reduce energy based inflation, a tight monetary policy is not feasible even if the demand channel is the prevailing monetary transmission channel. This is because the cost side effects of oil prices will strengthen the cost side effect of monetary tightening and the net result will be the dominance of the cost side effects. 


\section{References}

1. Gibson, A.H., 1923, The Future Course of High Class Investment Values, Banker's Magazine (London) 115, 15-34.

2. Tooke (1838), A history of prices and of the state of circulation from 1793 to 1837, reprint London PS King and son (1928)

3. Barth III, M. J., \& Ramey, V. A. (2001). The Cost Channel of Monetary Transmission. (B. S. Bernanke, \& K. Rogoff, Eds.) NBER Macroeconomics Annual $2001,16,199-239$.

4. Mishkin, F. S. (1995). Symposium on the Monetary Transmission Mechanism. The Journal of Economic Perspectives , 9 (4), 3-10.

5. Ghaffari A (2013), Interest Rate, Inflation and Output; Relationship Revisited, Unpublished MS Economics thesis, International Islamic University, Islamabad

6. Keynes J. M. (1936), The General Theory of Employment, Interest and Money, Macmillan Cambridge University Press, for Royal Economic Society, London

7. Sims, Christopher A. (1992), "Interpreting the Macroeconomic Time Series Facts: The Effects of Monetary Policy," European Economic Review 36 (June): 975-1000

8. Blinder, A. (1987). Credit rationing and effective supply failures. The Economic Journal 97(386):327-352

9. Farmer, R. (1984). A new theory of aggregate supply. American Economic Review 74(5):920-30 